\title{
A EXCLUSÃO DE SÓCIO INCAPAZ NA SOCIEDADE LIMITADA: ANÁLISE À LUZ DO PRINCÍPIO DA FUNÇÃO SOCIAL DA EMPRESA
}

\author{
João Luis Nogueira Matias \\ Professor do Programa de Pós-Graduação da Faculdade de \\ Direito da Universidade Federal do Ceará e da Faculdade 7 \\ de Setembro. Pós-Doutor em Direito Econômico pela \\ Faculdade de Direito da Universidade de Lisboa. Doutor \\ em Direito Comercial pela Faculdade de Direito da \\ Universidade de São Paulo. Doutor em Direito Público pela \\ Faculdade de Direito do Recife da Universidade de \\ Pernambuco. Juiz Federal. \\ joaoluisnm@uol.com.br.

\section{Davi Guimarães Mendes} \\ Mestrando em Direito Civil pela Universidade de São Paulo \\ (USP). Bacharel em Direito pela Universidade Federal do \\ Ceará (UFC). \\ davi.guimaraesmendes@gmail.com.
}

RESUMO: O presente trabalho tem, como objetivo, esclarecer em quais hipóteses é possível, na sociedade limitada, a exclusão de sócios em função de incapacidade superveniente, o que se faz necessário principalmente diante das divergências doutrinárias em relação a possibilidade de exclusão por esse motivo e seus requisitos de aplicação. Para isso, realiza-se um breve apanhado histórico das noções de função social, delineando sua evolução histórica, e se apresentando, em seguida, uma definição do princípio da função social da empresa. Por fim, faz-se uma análise crítica dos principais entendimentos acerca desta questão, buscando-se, em face deles, chegar a um melhor critério de aplicação do instituto, utilizando-se como paradigma teórico o princípio da função social da empresa.

PALAVRAS-CHAVE: Exclusão de sócio; Incapacidade civil; Função social da empresa; Sociedade limitada; Código Civil de 2002

The exclusion of the incapable shareholder in the Brazilian limited liability company: analysis under the principle of the social function of the company

ABSTRACT: This paper has, as objective, making clear in which hypothesis it is possible, in the Brazilian limited liability company, the exclusion of the shareholders in consequence of an incidental incapacity, which is needed mainly in the face of doctrinal divergences about the possibility of exclusion for this reason and its application requirements. In order to do this, a brief historical overview of the notions of social function is carried out, outlining its historical evolution, and presenting, after this, a definition of the principle of the social function of the company. Lastly, a critical analysis of the main understandings concerning to this question is made, seeking to, in face of them, reach a better application criteria to the institute, using as a theoretical paradigm the principle of the social function of the company.

Recebido em: 5 jun. 2016. Avaliado em: 10 set. e 4 nov. 2016.

R. Jur. FA7, Fortaleza, v. 13, n. 2, p. 13-23, jul./dez. 2016 
A exclusão de sócio incapaz na sociedade limitada: análise à luz do princípio da função social da empresa

KEYWORDS: Shareholder exclusion; Civil incapacity; Social function of the company; Limited liability company; 2002 Brazilian Civil Code.

\section{INTRODUÇ̃̃o}

A possibilidade de exclusão de sócios incapazes é matéria que apresenta grandes divergências doutrinárias, sobretudo quando estudada nas sociedades limitadas, modelo societário utilizado por empresas de pequeno e de grande porte, e que apresenta desafios de sistematização em face dessa versatilidade.

Recai a discussão na possibilidade ou não de se excluir da sociedade limitada um sócio por conta de sua incapacidade superveniente, questionando-se quais seriam os critérios para que o sócio incapaz seja excluído da sociedade limitada.

Pretende o presente estudo contribuir para esclarecer as hipóteses em que pode haver, nas sociedades limitadas, exclusão de sócio por conta de incapacidade superveniente, construindose, para isso, análise calcada no princípio da função social da empresa.

Para responder ao questionamento, far-se-á, por meio de uma metodologia exploratória, consistente principalmente em análise bibliográfica, uma breve narrativa histórica da ideia de função social, demonstrando-se, sobretudo, sua evolução histórica, passando-se, em seguida, a uma caracterização e definição em específico do princípio da função social da empresa.

Por fim, analisa-se de forma crítica as principais teses doutrinárias acerca do instituto da exclusão de sócio, perquirindo-se a justificativa para sua existência e qual seria a sua finalidade, realizando igualmente uma análise dos mais relevantes posicionamentos relativos à exclusão de sócio incapaz nas sociedades limitadas, procurando-se, logo em seguida, estabelecer critérios para a aplicação desse instituto à luz do princípio da função social da empresa.

\section{NOTAS ACERCA DO HISTÓRICO DA FUNÇÃO SOCIAL}

Cumpre esclarecer, de antemão, a distinção entre a estrutura de um instituto e a função por ele desempenhada. Consoante lição de Francisco Loureiro (2003, p. 109), o estudo estrutural de uma norma ou instituto seria realizado por meio de abordagem técnico-jurídica, preocupada em descrever as características jurídicas do objeto de estudo, ao passo que uma investigação funcional teria origem sociológica, orientada pela finalidade concreta assumida pelo fenômeno jurídica na realidade social.

Nesse sentido, Francisco Amaral (2008, p. 345) aponta que a função de uma norma ou instituto seria o papel por ela desempenhado no interior de sua estrutura, isto é, a finalidade social cuja consecução é almejada por meio de suas características jurídicas particulares.

Esta posição é também adotada por Francisco Loureiro (2003, p. 109-110), o qual sustenta que "o termo função, contraposto ao termo estrutura, serve, de fato, para definir o concreto modo de operar de um instituto ou de um direito de características morfológicas particulares e manifestas".

Segundo Tepedino (2012, p. 1), a função social, antes mesmo de se concretizar como princípio jurídico, surgiu, no auge do liberalismo individualista do século XIX, como postulado 
metajurídico que atribuiria a proteção jurídica de certos institutos à função econômica que desempenhavam na sociedade. Isto é, servia a função social para justificar a tutela jurídica de certo instituto, dada a sua relevância econômico-social (GOMES, 2002, p. 20).

Assumia o direito, à época, caráter unicamente estruturalista, havendo maiores preocupações em como estava ele estruturalmente posto no ordenamento jurídico, do que propriamente com sua função na sociedade e em que medida ele a alcançava (BOBBIO, 2007, p. 53).

Com a ascensão do Estado Social, no início do século XX, natural foi a redefinição do conceito de função social. Tratando pioneiramente desta temática, cita-se a Constituição Mexicana de 1917 e a Constituição Alemã de 1919, notando Didier Jr. (2008, p. 7) que, nesta última, celebrizou-se a previsão de que "a propriedade obriga".

É nessa época, também, que há pela primeira vez uma adoção expressa da noção de função social pelos ordenamentos jurídicos, afastando-se o conceito de função social daquele pretérito, característico do Estado Liberal, e que a reduzia, sob uma perspectiva individualista, à função econômica, passando a função social a ter verdadeiro caráter de valorização da coletividade, como aponta Polido (2016, p. 14):

Com relação à função social da propriedade, o artigo 153 da Constituição de Weimar
primeiro estabelece a garantia e os efeitos vinculativos (Bindungseffekte) da propri-
edade privada, especialmente decorrentes da expressão "a propriedade obriga" (das
Eigentum verpflicht). O modelo ali adotado prevê que a propriedade possa ser objeto
de desapropriação por meio de lei, sem eventualmente incluir direito de indenização.
Na concepção de Weimar, a propriedade não admite uma abordagem individualista,
inviolável ou sacralizada, pois submete o exercício pelo titular ao interesse da cole-
tividade.

É apenas nesse momento que vem a se reconhecer que o direito, para além da sua perspectiva estruturalista, que analisa como ele é elaborado para se concluir qual sua estrutura, tem também um caráter promocional, cuja análise é funcional, indagando-se para que o direito serve a fim de se determinar quais devem ser as atitudes a serem incentivadas (BOBBIO, 2007, p. 53).

Neste azo, atestam Farias e Rosenvald (2014, p. 139) que em toda relação jurídica é possível se encontrar uma estrutura e uma função, consistindo esta na promoção de atos socialmente desejáveis.

É em tal época, igualmente, que se passa a conceber uma isonomia material, e não apenas formal, diferenciando-se as duas na medida em que esta prevê simplesmente o tratamento idêntico de todos os indivíduos, ao passo que aquela, a fim de efetivar a igualdade, propõe tratamento distinto àqueles que são diferentes, na medida em que assim o são (ROCHA, 1990, p. 39).

Nada obstante, era, até então, a função social mera proposição ética, norma programática que devia conduzir a sociedade aos fins propostos, sem ter, contudo, aplicação imediata ou mesmo reconhecimento dos aplicadores do direito, que permaneciam aplicando o paradigma liberal, privando de eficácia as normas constitucionais referentes à função social (AUAD, 2009, p. 339-340).

Foi nesse contexto que a noção de função social foi incorporada ao ordenamento jurídico brasileiro, tendo efetivamente constado no texto constitucional do Brasil pela primeira vez na Constituição Federal de 1946, por meio da previsão da função social da propriedade (CORREIA, 2009, p. 68).

Explica Cambi (2007, p. 4-6)que, passada a Segunda Guerra Mundial e verificadas as imperfeições do positivismo jurídico e do constitucionalismo clássicos, passa-se a procurar um referencial jurídico hábil a resguardar valores importantes à sociedade, isto é, tenta-se ir além da 
mera legalidade - observância das leis ordinárias —, o que leva até o desenvolvimento das doutrinas pós-positivista e neoconstitucionalista, em que há uma valorização da Constituição como diploma ideal para a proteção dos direitos fundamentais, sobretudo em seus princípios, concedendo-se a estes aplicabilidade imediata.

Segundo Pimenta (1999, p. 188), é a Constituição Federal de 1988, no Brasil, o marco da adoção desses ideais, sendo garantida a aplicabilidade imediata dos direitos fundamentais em seu Art. $5^{\circ}, \S 1^{\circ}$. Didier Jr. (2008, p. 9) explica, ainda, que é a partir deste momento que o princípio da função social passa de norma de caráter meramente programático a norma de assegurada aplicabilidade.

Esses acontecimentos muito influenciaram o direito privado, principalmente em face da concepção de que há a necessidade de se adequar a interpretação da legislação ordinária do Código Civil às normas constitucionais, e não vice-versa (TEPEDINO, 2006, p. 21).

É neste horizonte que se dá o processo de reinterpretação dos institutos clássicos sob a nova ordem constitucional (BARROSO, 2007, p. 20), afirmando Perlingieri (2007, p. 12-13), sobre esta temática, que a norma constitucional passa, de mera auxiliar na interpretação das regras, a razão justificadora, ainda que não única, da relevância da tutela das relações jurídicas, redefinindo, por isso, os fundamentos e a extensão dos institutos jurídicos.

Percebe-se, portanto, a evolução histórica que a ideia de função social experimentou, passando, em verdade, de mera justificação da proteção jurídica de certos institutos, sem positivação, quem dirá aplicabilidade, no contexto do Estado Liberal, a norma jurídica que visava a submissão da propriedade — aqui inclusa a empresa, como irá se expor a seguir — a interesses da coletividade, mas ainda sem aplicabilidade imediata, no contexto do Estado Social, até o paradigma atual de reconhecimento da eficácia jurídica do princípio da função social, sendo dotada de aplicabilidade imediata.

\section{A FUNÇÃO SOCIAL DA EMPRESA}

No que pese inexistir previsão expressa do princípio da função social da empresa, é imperioso se admitir que é também a propriedade empresarial adstrita à observância de uma função social, em função sobretudo da dimensão que assumem as empresas na organização socioeconômica moderna (MARTINS-COSTA, 2005, p. 41).

Em verdade, o que se verifica é que o princípio da função social da empresa decorre diretamente do princípio da função social da propriedade, sendo constitucionalmente assegurado, por conseguinte, e repercutindo no exercício da atividade empresarial e conformando o exercício da propriedade empresarial, por parte dos sócios, também ao interesse da coletividade (MATIAS, 2009, p. 76-79).

Com o reconhecimento de um princípio da função social da propriedade, de agora inegável aplicabilidade, aponta Correia $(2009$, p. 22) que o que se observa é uma funcionalização do direito de empresa, afastando-se o conteúdo deste dos contornos individualistas de outrora.

Em sentido semelhante, cita-se lição de Matias (2009, p. 87): “A nova concepção de propriedade se irradia sobre o direito empresarial, não sendo facultado ao proprietário de empresas, sócios ou acionistas exercerem abusivamente o direito que lhes é assegurado constitucionalmente". 
Necessário, por conseguinte, delimitar-se o conteúdo jurídico do princípio da função social da propriedade a fim de se alcançar compreensão mais exata acerca de suas repercussões na funcionalização da propriedade empresarial.

Retomando a distinção entre a análise estrutural e funcional do fenômeno jurídico, Francisco Loureiro (2003, p. 110) afirma que o princípio da função social da propriedade, porquanto norma cogente, dotada de eficácia jurídica, não pode se limitar a indicar um estudo sociológico dos interesses metajurídicos tutelados pelo instituto, tratando-se, em verdade, um de seus elementos.

Isto é: a função social da propriedade se insere na própria estrutura do instituto, não podendo ser considerada como uma mera remissão do legislador às necessidades sociais e econômicas por ele atendidas.

Por força de sua função social, a propriedade passa a ser entendida não só como um direito do proprietário, mas como situação jurídica complexa, de modo que gera também, ao lado das faculdades de usar, fruir e dispor, uma série de obrigações perante terceiros individualizados e a coletividade, concernentes tanto em abstenções quanto em prestações ativas (LOUREIRO, 2003, p. 122-123).

Em paralelo com essa noção de função social da propriedade, a funcionalização da empresa implica, sobretudo, na instrumentalização desse direito patrimonial à consecução não só dos interesses individuais, mas também dos da coletividade. Sintetizando essa visão, afirma Matias $(2009$, p. 87) que o princípio da função social da empresa representa:

[...] a vinculação do exercício da empresa à concretização de uma sociedade livre,
justa e solidária, do que decorre um complexo de deveres e obrigações, positivas e
negativas, impostas aos controladores e administradores, perante os empregados, for-
necedores, consumidores, meio ambiente, Estado, e toda a comunidade que com ela
interage. Também são emanações da função social da empresa o incentivo à sua pre-
servação e a obrigação de proteção aos sócios minoritários. Trata-se, assim, de prin-
cípio jurídico, que pode ter a sua efetividade exigida, não mera proposição de cunho
moral.

Em função do princípio ora em comento, revela-se uma evolução da noção de propriedade empresarial, assumindo esta, modernamente, uma significativa importância não só econômica, mas social, e contribuindo para a materialização de uma sociedade nos moldes previstos na Constituição Federal de 1988. Nessa esteira, a empresa, além de atender aos interesses de seus sócios, cria para eles uma série de obrigações.

Conforme escólio de Martins-Costa (2005, p. 51),consequência dessa importância da empresa na vida comunitária é a existência de deveres da sociedade para com a empresa, como o de preservá-la, e da empresa perante a coletividade, como o de resguardar o meio ambiente, impondo-se ainda um certo tipo de atuação por parte dos sócios daquela, que além de também serem obrigados a contribuir para preservá-la, devem exercer a atividade empresarial no interesse da empresa, ou seja, de todos os sócios, principalmente quando desempenharem papel de controle, pelo que se nota uma aproximação das relações internas da empresa à ideia de isonomia substancial prevista na Constituição Federal de 1988.

Alcança-se modernamente, portanto, o entendimento de que o princípio da função social da empresa, de natureza constitucional, por ser corolário do princípio da função social da propriedade, deve não mais ser vislumbrado como norma programática despida de qualquer eficácia, como se proposição ética fosse, mas sim como verdadeiro princípio jurídico que, como tal, tem aplicabilidade imediata, e cujo conteúdo consiste, sobretudo, na percepção da empresa como 
A exclusão de sócio incapaz na sociedade limitada: análise à luz do princípio da função social da empresa

instrumento não só do alcance dos interesses individuais dos sócios, mas da persecução de objetivos socialmente relevantes, que têm implicações nas relações internas e externas da empresa.

\section{A EXCLUSÃo DE SÓCIOS INCAPAZES NA SOCIEDADE LIMITADA}

Ensina Nunes (2002, p. 23) que a exclusão de sócios é instituto que divide posições doutrinárias acerca da sua caracterização, sendo três as principais correntes.

Em primeiro lugar, a teoria do poder corporativo disciplinar, que aponta que a sociedade empresária poderia excluir seus membros nos casos previstos por lei ou instrumento social, em aplicação de poder disciplinar do qual seria dotado o ente coletivo sobre aqueles que o constituiriam, simetricamente ao poder disciplinar da Administração Pública sobre seus agentes (NUNES, 2002, p. 32).

Critica-se esse posicionamento, todavia, por ignorar que a expulsão de sócios nem sempre tem caráter disciplinar, acontecendo, por vezes, simples com o preenchimento de certos requisitos legais ou contratuais (NUNES, 2002, p. 32-33).

Outra teoria acerca desta matéria seria a da disciplina taxativa legal, que defende que, em face da importância econômico-social da empresa, seria de interesse público a sua conservação, atribuindo caráter público ao instituto (NUNES, 2002, p. 25), ao que se teceriam críticas pelo fato de que esse instituto se fundaria principalmente no interesse privado dos sócios, sendo o interesse público no caso em questão apenas reflexo, coincidente no mais das vezes com o interesse particular dos sócios, apontando-se como falha igualmente a taxatividade legal defendida pela teoria e o caráter exclusivamente sancionatório da expulsão(NUNES, 2002, p. 33-38).

Por fim, a teoria contratualista, majoritária na Itália, e inspirando-se tanto no instituto da resolução contratual por inadimplemento quanto no princípio da preservação da empresa, explica que a exclusão dos sócios seria fundada no descumprimento de deveres sociais por parte dos membros do ente coletivo, o que justificaria suas expulsões, completando parte dos doutrinadores que a lei ou os instrumentos sociais poderiam prever outras cláusulas resolutivas expressas que independessem de inadimplemento (NUNES, 2002, p. 26-28).

Apesar das críticas à abordagem da exclusão de sócios como resolução contratual (NUNES, 2002, p. 38-39), afigura-se essa como a melhor solução, eis que afasta do instituto o caráter de sanção, adequando-o à característica de contrato plurilateral que assume o instrumento constituinte da sociedade empresária, ao passo que valoriza o princípio da preservação da empresa, corolário do princípio da função social da empresa.

Por outro lado, ao tratar da matéria da exclusão de sócios na sociedade limitada, conforme regulada na ordem jurídica brasileira, Coelho (2014, p. 447) aponta quatro hipóteses em que esta pode se dar: a) quando o sócio descumpre seus deveres; b) quando as quotas deste forem liquidadas a pedido de credor; c) quando entra ele em falência; d) quando é declarado incapaz.

Na primeira situação, constituir-se-ia a expulsão em sanção, opinião da qual se discorda, haja vista se tratar esse caso não de sanção, mas de hipótese de resolução por inadimplemento dos deveres do sócio, podendo acontecer de forma extrajudicial quando em relação ao sócio minoritário, desde que obedecendo ao procedimento previsto pelo Art. $1.085 \mathrm{do} \mathrm{CC} / 02$, enquanto nos demais casos não teria a exclusão do sócio caráter sancionatório, sendo igualmente possível nessas hipóteses a exclusão extrajudicial, com exceção da expulsão do sócio incapaz, que só poderia ser decretada pelo juiz (COELHO, 2014, p. 448-451). 
Em se falando especificamente da exclusão do sócio incapaz, Coelho (2014, p. 451) afirma, com fulcro no Art. 1.030, caput, do CC/02, aplicado subsidiariamente às sociedades limitadas, que basta que a incapacidade se dê supervenientemente, isto é, após a constituição da sociedade, para que se possa proceder com a expulsão daquele.

Não nos parece, contudo, acertado o posicionamento. A exclusão do sócio, como anteriormente exposto, trata-se de cláusula resolutiva que pode ser fundada no inadimplemento por parte do sócio de seus deveres enquanto membro da sociedade ou em outras previsões legais ou convencionais, justificando-se a expulsão sempre na conservação da empresa.

Ora, o entendimento de que a incapacidade superveniente do sócio é motivo de resolução da sociedade em relação a este, independentemente de prejuízo à sociedade, representa interpretação que, além de equivocada, por afastar o instituto em comento do princípio da preservação da empresa, concede à norma caráter flagrantemente inconstitucional, porquanto atentatória ao princípio da isonomia, previsto no Art. $5^{\circ}$, caput, da Constituição Federal de 1988, ao discriminar de forma imotivada os sócios incapazes.

Em sentido diametralmente oposto, Carvalhosa assevera (2003, p. 311) que a incapacidade superveniente do sócio não poderia jamais ser aplicada às sociedades limitadas, pois incompatível com o seu caráter misto, de capital e de pessoas, que o autor atribui a essas sociedades, o qual não se compatibilizaria com essa hipótese de expulsão.

Assiste certa razão ao doutrinador, que aponta que a sociedade limitada não tem o caráter presumidamente pessoal que assumem as sociedades simples, por exemplo. Nada obstante, falha ele ao afastar completamente das sociedades limitadas a aplicabilidade desse instituto, aparentemente ignorando as hipóteses em que se verifica a existência de laços pessoais unindo os sócios das sociedades limitadas, situações em que a incapacidade superveniente de um deles poderia representar grave risco à continuidade da empresa.

Cita-se, como exemplo, o caso de empresas pequenas, em que comumente todos os sócios exercem atividades que viabilizam a consecução do objeto social, hipótese em que a incapacidade de um deles poderia representar a inviabilidade da atividade empresarial.

Se fosse adotada a posição expressada pelo autor, na situação narrada os demais sócios não poderiam excluir o incapaz, devendo esperar que seus atos ou omissões causassem efetivo dano à empresa, o que representaria um grande perigo à continuidade da sociedade, na contramão da preservação da empresa e, por conseguinte, do princípio da função social da empresa.

Adotando posição intermediária, Vio (2008, p. 145-146) afirma que só seria possível a exclusão dos sócios por incapacidade superveniente quando estivesse previsto no contrato social algum dever deste em relação à sociedade que não mais pudesse ser realizado em face da sua incapacidade, o que se justificaria no fato de que nas sociedades limitadas não seria intrínseco aos sócios nenhum outro dever de colaboração para a consecução do objeto social além da contribuição para a integralização do capital social.

No que pese o valor da posição em questão, por evidenciar que a exclusão do sócio incapaz estaria relacionada ao papel que ele assumiria junto à sociedade, posição que vai na esteira de que a expulsão deve servir como forma de preservação da sociedade, peca o autor ao pretender vincular a utilização do instituto à existência de previsão, no contrato social, de deveres de colaboração que não mais poderiam ser desempenhados por conta da incapacidade superveniente, requisito que impossibilitaria a exclusão mesmo quando se constatasse, no caso concreto, a ameaça que a incapacidade do sócio representaria à empresa. 
Em verdade, a exclusão do sócio incapaz tem aplicação exatamente nos casos de empresas pequenas e médias, em que habitualmente as previsões do contrato social não atendem às minúcias pretendidas pelo doutrinador. Estaria praticamente despida de eficácia, portanto, a exclusão por incapacidade superveniente.

Melhor critério para que se meça a aplicabilidade da expulsão do sócio incapaz à sociedade limitada é a análise da finalidade do instituto da exclusão de sócios, atentando-se ao princípio da função social da empresa, que deve guiar a atuação empresarial.

Explicando a precípua finalidade do instituto em comento, tem-se Nunes (2002, p. 4849), que afirma:

\begin{abstract}
A natureza e a função social das sociedades comerciais é que faz delas factores de enorme interesse social, saltando para fora do âmbito dos contratos de mero interesse dos participantes. As empresas comerciais representam um valor económico de organização que é necessário conservar, para salvaguarda do esforço organizador dos empresários, do direito dos empregados ao trabalho, dos direitos dos sócios a ver frutificar o seu capital. A ordem jurídica deve, portanto, facilitar o afastamento daquele sócio cuja presença é elemento pernicioso para o seu normal funcionamento e para a prosperidade da sua empresa.
\end{abstract}

Em sentido similar, tem-se a lição de Comparato (1997, p. 41), que explica que a resolução parcial da sociedade atende a uma necessidade de proteção da atividade empresarial, visando à sua continuidade, porquanto reconhecida juridicamente a sua relevância social e econômica.

A exclusão de sócios, inclusive daquele incapaz, deve se guiar, portanto, pelo objetivo de preservar a empresa, o que justifica na sua função social enquanto produtora e distribuidora de riquezas e instrumento de construção de uma sociedade justa, livre e solidária. Nessa esteira, ressai como critério por excelência para a aplicação do instituto em questão o risco que pode a incapacidade superveniente do sócio representar para a continuidade da sociedade empresária. Essa ameaça se revela na impossibilidade do sócio de cumprir algum de seus deveres perante a sociedade, prejudicando suas atividades e arriscando a sua preservação.

Não prejudicando a incapacidade civil a situação patrimonial do sócio, entretanto, podese afirmar, de antemão, que quando a sociedade limitada se organizar como sociedade de capitais — isto é, quando forem livremente cessíveis as quotas — não cabe a exclusão do sócio que por ventura se tornar incapaz. Ora, em empresas desse tipo o sócio é um mero prestador de capital, não representando a sua incapacidade superveniente prejuízo à continuidade da atividade empresarial.

Por outro lado, quando for sociedade de pessoas a limitada, vislumbrando uma participação e importância do sócio que vá além de sua prestação pecuniária referente à integralização do capital social, é possível a exclusão do sócio incapaz. Ao se aplicar esse instituto, contudo, é necessário ter-se olhos ao caso concreto, devendo sempre se comprovar que o sócio acometido pela incapacidade tinha, de fato, participação na sociedade que superasse o mero investimento financeiro e que restara impossibilitada por conta de sua situação, sendo necessário ainda se provar que isso representaria prejuízo à sociedade que ameaçaria a sua preservação.

Não basta ser a limitada uma sociedade de pessoas para que o sócio incapaz possa ser excluído, portanto. É necessário igualmente que seja observado uma ameaça à continuidade da empresa resultante de sua incapacidade, em face de um dever seu em relação à sociedade que não mais poderá ser cumprido.

Cumpre destacar, por fim, que os deveres de colaboração do sócio devem ser constatados à luz do caso concreto, e não pela mera observação do contrato social. 
Isso porque a exclusão do sócio não se relaciona à previsão no instrumento social de um dever de colaboração que teria sido infringido pelo sócio — aceitar isso seria acolher a já refutada teoria do poder corporativo disciplinar —, mas sim com uma necessidade de preservação da empresa justificada no princípio da função social da empresa.

Tem-se, assim, uma cláusula resolutiva legal da sociedade em relação ao sócio que, por conta de incapacidade superveniente, não pode mais cumprir um dever assumido em face à sociedade, constatado sempre no caso concreto, prejudicando assim a empresa e ameaçando a sua continuidade.

Apesar de as conclusões sustentadas serem plenamente aplicáveis à ordem jurídica pátria em seu estado atual, por significarem interpretação do Art. 1.030 do Código Civil de 2002 à luz do princípio da função social da empresa, é importante que à matéria seja conferido tratamento legislativo aprimorado, que afaste dúvidas quanto ao significado da norma em discussão.

Sendo assim, propõe-se, de lege ferenda, que à redação do dispositivo discutido seja incluída, após a menção à incapacidade superveniente como causa de exclusão do sócio, a ressalva de que esta só seria possível quando impusesse "risco à continuidade da empresa, verificado na impossibilidade de cumprimento, por parte do sócio incapaz, de prestações fundamentais à consecução do objeto social".

Isto posto, tem-se que o instituto da exclusão do sócio representa uma aplicação do princípio da função social da empresa, mais particularmente no que se refere à preservação desta. Deste modo, só é possível a expulsão do sócio incapaz quando este representar um risco à continuidade da sociedade, o que não se dá na generalidade dos casos, mas, conforme demonstrado, apenas nas sociedades limitadas que são sociedades de pessoas e somente quando houver por parte do sócio incapaz um dever de colaboração em relação à empresa que, não mais exercido por conta da incapacidade, represente um risco à preservação desta. Ademais, é interessante que haja o aprimoramento do tratamento legislativo da matéria, explicitando-se, na redação do Art. 1.030 do Código Civil de 2002, que o ali previsto só é aplicável em havendo risco à continuidade da empresa.

\section{CONCLUSÕES}

No presente trabalho, estudou-se a exclusão motivada por incapacidade nas sociedades limitadas, procurando estabelecer seus critérios de aplicação com base no princípio da função social da empresa.

Primeiramente se expôs um panorama histórico da função social, desde sua origem como postulado metajurídico que justificava a tutela de certas matérias pelo direito, até o cenário atual, em que se reconhece a sua imediata aplicabilidade e caráter constitucional, chegando-se inclusive a desdobramentos da funcionalização patrimonial, tais como a função social dos contratos e da empresa.

Em segundo lugar, analisou-se de forma mais detida o princípio da função social da empresa, demonstrando ser ele corolário do princípio da função social da propriedade, sendo de ordem constitucional, portanto. Ademais, buscou-se esclarecer seu significado, concluindo-se que se trata de princípio que busca funcionalizar a empresa para se alcançar não só os interesses privados, mas também interesses da coletividade, o que tem desdobramentos práticos tais como a procura de igualdade substancial dentro das relações empresariais, com a proteção dos sócios minoritários, dos trabalhadores e daqueles que contratam com a empresa, bem como a preservação desta, eis que de assumida relevância social e econômica na atualidade. 
Por fim, investigou-se as construções doutrinárias acerca do instituto da exclusão de sócios e, de forma mais específica, em relação à exclusão de sócios incapazes na sociedade limitada, apresentando-se e tecendo-se críticas aos principais posicionamentos.

No que se refere à definição dos critérios de aplicação, concluiu-se que, para determinalos, há de se atentar ao princípio da função social da empresa, que justifica a possibilidade da exclusão de sócios ao zelar pela preservação daquela.

Imperioso, por conseguinte, que o instituto só seja utilizado quando a incapacidade superveniente do sócio importar risco à continuidade da sociedade, o que só se pode verificar nas sociedades limitadas que são sociedades de pessoas, e apenas nos casos em que o sócio tenha algum dever de colaboração, a ser aferido no caso concreto, que diante de sua condição não mais poderá ser desempenhado, representando prejuízo à empresa que ameace a sua preservação.

Ademais, no que pese estes critérios já serem aplicáveis, por se tratarem de delimitação do instituto da exclusão de sócios, à luz do princípio da função social da empresa, é importante que haja o aprimoramento do tratamento legislativo da matéria, sugerindo-se, de lege ferenda, que se acrescente à redação do Art. 1.030 do Código Civil de 2002 que a exclusão de sócio por capacidade superveniente só seria possível quando impusesse "risco à continuidade da empresa, verificado na impossibilidade de cumprimento, por parte do sócio incapaz, de prestações fundamentais à consecução do objeto social".

\section{REFERÊNCIAS}

AMARAL, Francisco. Direito civil: introdução. 7. ed. Rio de Janeiro: Renovar, 2008.

AUAD, Denise. Os direitos sociais na constituição de Weimar como paradigma do modelo de proteção social da atuação Constituição Federal brasileira. Revista da Faculdade de Direito da Universidade de São Paulo, São Paulo, v. 103, p. 337 - 355, jan./dez., 2008.

BARROSO, Luís Roberto. Neoconstitucionalismo e constitucionalização do direito: o triunfo tardio do direito constitucional no Brasil. Revista Eletrônica sobre a Reforma do Estado, Salvador, n. 9, p. 01 - 41, mar./maio, 2007.

BOBBIO, Norberto. Da estrutura à função: novos estudos de teoria do direito. Tradução de Daniela Beccaccia Versiani; revisão técnica de Orlando Seixas Bechara, Renata Nagamine. Barueri: Manole, 2007. Título original: Dalla struttura alla funzione.

CAMBI, Eduardo. Neoconstitucionalismo e neoprocessualismo. Panóptica, ano 1, n. 6, p. 1 44, fev., 2007.

CARVALHOSA, Modesto. Comentários ao código civil: parte especial — do direito de empresa. In: AZEVEDO, Antônio Junqueira (Coord.). Comentários ao Código Civil. São Paulo: Saraiva, 2003. v. 13.

COELHO, Fábio Ulhoa. Curso de direito comercial: direito de empresa. 18. ed. São Paulo: Saraiva, 2014, v. 2.

COMPARATO, Fábio Konder. A exclusão de sócios na sociedade limitada de acordo com o código civil de 2002. Revista de Direito Mercantil, n. 25, 1997, p. 39-48.

CORREIA, Edmar. A função social do contrato. Rio de Janeiro, 2009. 115 p. Dissertação apresentada ao Programa de Pós-Graduação da Faculdade de Direito da Universidade Estadual do Rio de Janeiro, Mestrado em Direito Civil, para obtenção do título de mestre em Direito Civil. 
DIDIER JUNIOR, Fredie. A função social da propriedade e a tutela processual da posse. Disponível em: <http://www.mpma.mp.br/arquivos/CAOPDH/a-funcao-social-e-a-tutela-daposse-fredie-didier.pdf $>$. Acesso em: 11 mar. 2015.

FARIAS, Cristiano Chaves; ROSENVALD, Nelson. Direito civil. 8. ed. Salvador: Juspodivm, 2014, v. 4.

GOMES, Orlando. Contratos. 25. ed. Rio de Janeiro: Forense, 2002.

LOUREIRO, Francisco Eduardo. A propriedade como relação jurídica complexa. Rio de Janeiro: Renovar, 2003.

MARTINS-COSTA, Judith. Reflexões sobre o princípio da função social dos contratos. Revista Direito GV, São Paulo, v. 1, n. 1, p. 41 - 66, maio, 2005.

MATIAS, João Luís Nogueira. A função social da empresa e a composição de interesses na sociedade limitada. São Paulo, 2009. 323 p. Tese apresentada à banca examinadora da Faculdade de Direito da Universidade de São Paulo, para obtenção do título de doutor em Direito Comercial.

. A propriedade e a ética empresarial: a distinção entre a função social da empresa e a teoria da social responsability. In WACHOWICZ, Marcos; MATIAS, João Luís Nogueira (Coord.). Direito de Propriedade e Meio Ambiente: novos desafios para o Século XXI. Florianópolis: Fundação Boiteux, 2010.

NUNES, Antônio José Avelãs. O direito de exclusão de sócios nas sociedades comerciais.Coimbra: Almedina, 2002.

PERLINGIERI, Pietro. Perfis do direito civil: introdução ao direito civil constitucional. Tradução de Maria Cristina de Cicco. 3. ed. Rio de Janeiro: Renovar, 2007. Título original: Profili del diritto civile.

PIMENTA, Paulo. Eficácia e Aplicabilidade das normas constitucionais programáticas. São Paulo: Max Limonad, 1999.

POLIDO, Fabrício. Ensaio: A Constituição de Weimar de 1919 e o Conteúdo Normativo da "Função Social" dos Direitos Proprietários. Revista Trimestral de Direito Civil, Rio de Janeiro, v. 27 , p. $3-47,2006$.

ROCHA, Cármen Lúcia Antunes. O princípio constitucional da igualdade. Belo Horizonte: Lê, 1990.

TEPEDINO, Gustavo. Notas sobre a função social dos contratos. Disponível em: $<$ http://www.tepedino.adv.br/wp/wp-content/uploads/2012/09/biblioteca12.pdf $>$. Acesso em: 11 mar. 2015.

. Crise de fontes normativas e técnica legislativa na parte geral do Código Civil de 2002. In___ Temas de Direito Civil. Rio de Janeiro: Renovar, 2006.

VIO, Daniel de Ávila. A exclusão de sócios na sociedade limitada de acordo com o código civil de 2002. Dissertação (Mestrado em Direito Comercial). São Paulo, Faculdade de Direito da Universidade de São Paulo, 2008, 230 p. 